Management, Procurement and Law Volume 167 Issue MP3

Building information modelling and its effect on off-site construction in UK civil engineering

Vernikos, Goodier, Broyd, Robery and Gibb ice proceedings

\title{
Building information modelling and its effect on off-site construction in UK civil engineering
}

Vasileios K. Vernikos MSC

Research Engineer, CH2M HILL and Loughborough University, UK

Chris I. Goodier BEng, PhD, pgCert, MCIOB, MICT, FHEA

Senior Lecturer, Loughborough University, UK

Timothy w. Broyd BSC (Hons), PhD, FREng, FICE, FRSA

Vice-President, Institution of Civil Engineers, London, UK
Peter C. Robery BSC (Hons), PhD, FREng, FICE, FCS, MICT Technology Director, International Transportation, CH2M HILL

Alistair G. F. Gibb BSC, PhD, CEng, MICE, MCIOB

Professor, Loughborough University, UK

In 2011, the UK government mandated that, by March 2016, all public-sector construction projects would be undertaken within a three-dimensional building information model (BIM) environment. This has caused both construction procurers and providers to embark on a journey towards universal BIM adoption, including the integration of BIM within a revised construction process. In addition, off-site construction has seen significant development in the building sector in the past decade; however, in infrastructure, off-site constructionoff-site construction exploitation has been more limited. This paper presents findings from UK-focused research into how innovation initiatives such as BIM and off-site construction can and need to be considered together, thus allowing leaner design, a greater integration of lifetime project data and more novel technical solutions. Key themes that emerged from the thematic analysis of the interviews show the importance of configuration and interface management; information data flow; project management and delivery; procurement and contracts. The analysis outlines the benefits of utilising off-site construction within a BIM environment, the challenges currently facing the supply chain, and recommendations are made as to how best to implement the emergent benefits.

\section{Introduction}

mproving efficiency in construction has been on the agenda of the UK government and industry for many years (Wolstenholme, 2009); various attempts and initiatives have been documented, addressing different aspects of the construction industry (Wolstenholme, 2009). Recent initiatives - including building information modelling (BIM), lean construction and off-site construction - aim to reduce costs through improved resources and enhanced data management (Vernikos et al., 2011) with BIM becoming increasingly applied within UK construction in recent years. BIM implementation is occurring by means of a 'push-pull' process with BIM slowly embedded in various forms and methods in many current construction projects (NBS National BIM Library, 2013). The UK government wants to achieve a $20 \%$ saving in construction costs and aims to implement BIM in all government construction procurement contracts by 2016 (Morrell, 2011), with the expectation that it will contribute to the savings target. Many would consider this target to be a real challenge if achieved solely through the implementation of a single innovative initiative in such a short time.

Research literature (Bew and Underwood, 2010; Blismas et al., 2005; Goodier and Gibb, 2007; Larsson and Simonsson, 2012;
Nadim and Goulding, 2010; Venables et al., 2004; Wix, 1997) and industry reports (McGraw Hill Construction, 2010, 2011; Miles and Whitehouse, 2013; NBS National BIM Library, 2013) analyse barriers, drivers, implementation techniques and case studies for both BIM and off-site construction. The civil engineering sector is moving towards multi-dimensional objectoriented design in a similar way to the building sector. Many believe that this will inherently encourage the production of 'objects' designed for manufacturing, especially if data can be sent directly to the fabricators. Construction is a 'low information intensity' industry compared with banking or finance ( $\mathrm{Hu}$ and Quan, 2005). vertheless, civil structures are complex entities formed by various sub-systems and diverse components, many often of unique design. The continued reliance of the civil engineering industry on paper-based drawings as a means of recording designs and fabrication data is inhibiting off-site construction innovation.

Theoretically, with the 'digitalisation' of construction data it is expected that advanced automation in design, manufacturing and erection through BIM will increase off-site construction (Eastman and Sacks, 2008). BIM is the technology that allows construction data to be 'machine readable' and components to 
be manufactured without human intervention (Eastman and Sacks, 2008). The aim of this paper is to assess how BIM affects the realisation of off-site construction in civil engineering, particularly in the UK. Additional objectives are to analyse the current status of BIM development and to investigate how current industry leaders perceive the relationship between BIM and off-site construction for infrastructure.

\section{Methodology}

Grounded theory was applied in this research to allow for insights into investigating the emerging industry processes, while avoiding the adjusting or steering of data towards previous theoretical frameworks. It focused on a phenomenological approach and deductive-derived theory (Glaser and Strauss, 1967). Unlike other qualitative approaches, grounded theory begins by focusing on the conceptual scheme in a contextual way, avoiding any predetermined theory (Cassell and Symons, 2004). If any other method was adopted the theoretical framework would have constrained the research. Grounded theory allows for the hypotheses to be created after the data have been analysed (Strauss and Corbin, 1990). As the topic had not yet been researched, the hypothesis was not developed initially. The adoption of grounded theory also limited research bias. This investigation did not intend to focus on a distinct area, but rather to allow the research to unravel through a continuous comparative analysis of incoming data that enabled a conceptual development. The data collection period lasted 6 months and data were considered sufficient when 'theoretical saturation' occurred (Glaser and Strauss, 1967). The conceptual theory was initially established through a series of discussions with industry experts.

When the exact research question was identified, a thorough and focussed literature review was undertaken, including published research, industry reports and government regulations. Twelve semi-structured interviews were conducted with specialists for implementing BIM, representing leading UK construction contractors and consultants, global software vendors, UK engineering industry institutions and the UK government. The interviews were analysed thematically in six emergent areas: configuration management; construction management, scheduling and planning; interface management and information data flow; procurement and contract; object-oriented design; and modelling. These themes emerged from the data, rather than being preconceived from the literature, as part of the overall 'thematic analysis'. As the research considers data from the UK's largest consulting and contracting firms, the findings may apply predominantly to larger corporate firms. Methodological limitations are acknowledged as SMEs and suppliers were not included in the data collection process.

\section{Findings}

Many organisations, academic and industry experts have attempted to define BIM and off-site construction during the past decade. For this research, 12 experts first explained what each term meant to their organisation. BIM was seen by all as a platform for communication and collaboration. Furthermore, although the focus is on data and information, attention is drawn to the way the design or modelling processes are managed and controlled (Figure 1). Recurring terms such as 'correct' or 'improve' show a positive attitude and enthusiasm towards this innovation. To summarise, BIM is therefore an umbrella term for object-oriented modelling that relates to both vertical (i.e. buildings) and horizontal (i.e. railway, highways etc.) infrastructure, where the objects have extended attributes that can be leveraged to understand the content of a design and allow for a consistent platform of communication throughout the supply chain.

Off-site construction definitions were more diverse and sometimes contradictory (Figure 2). Contractors saw off-site construction as a construction process, where components are fabricated in a factory or somewhere near to site and then transported to site for installation. For consultants, off-site construction is more of a means to achieve increased efficiency where products, either bespoke or from a catalogue, are manufactured in a controlled factory environment and assembled on site. There was confusion between the terms standardisation, prefabrication and preassembly.

\subsection{Previous government initiatives}

Although off-site construction has been promoted by the UK government for generations, albeit using different terms such as prefabrication (Murray and Langford, 2008), the focus on high-powered information and communications technology has been somewhat more recent. In 2002, The Department for Trade and Industry (DTI) combined with the Engineering and Physical Sciences Research Council to develop a programme of works, the innovative manufacturing initiative (IMI). The IMI funded a theme called meeting clients needs through standardisation, which orchestrated a group of focused calls for research programmes. The last two programmes funded predominately by the DTI's partners in technology programme

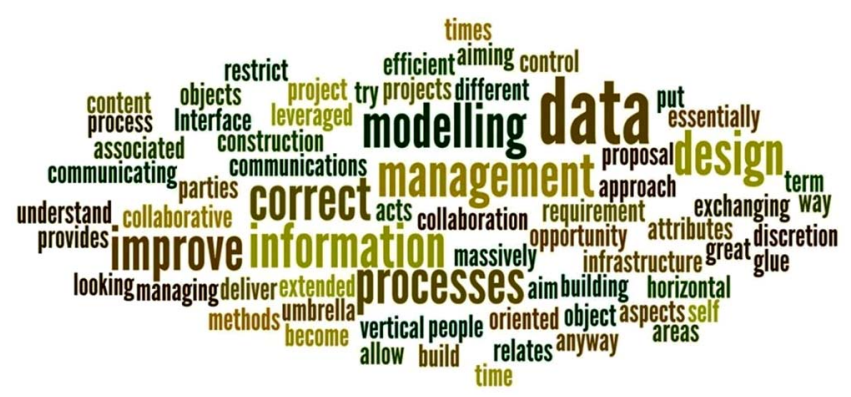

Figure 1. Key words from research participants' BIM definitions (Wordle, 2013). The size of the words above reflects their reoccurrence in the definitions discussed 


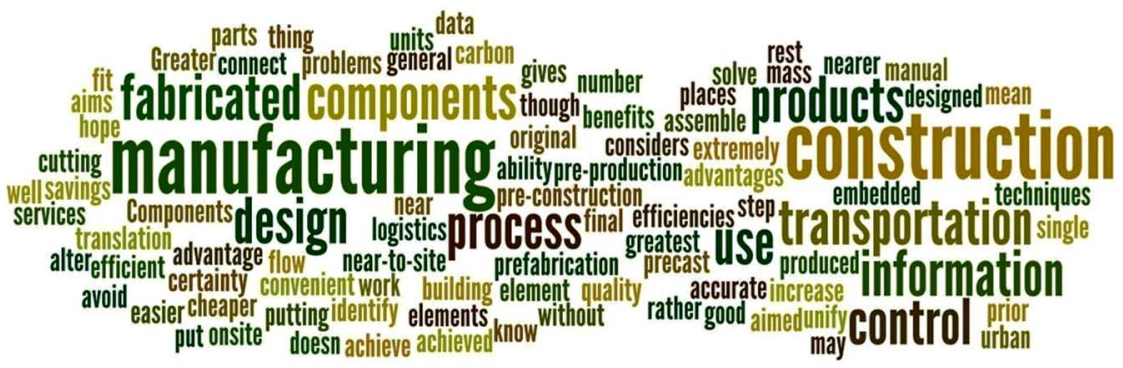

Figure 2. Key words from participants' off-site construction definitions (Wordle, 2013). The size of the words above reflects their re-occurrence in the definitions discussed

(currently known as Department for Business, Innovation and Skills (BIS)) were Avanti and PrOSPa. Avanti's core aim was to investigate and encourage collaboration through the use of computer aided design by arguing that managing information databases was more efficient than managing 'drawings in a cabinet' (Construction Project Information Committee, 2007). Avanti supported early access to information from all parties of the supply chain and work protocols, promoting improved communication and common information models, and was a stepping stone on the way to the current government BIM initiative. PrOSPa aimed to encourage off-site construction solutions across the construction sector (Goodier and Gibb, 2007). PrOSPa was the predecessor to the industry-focused organisation Buildoffsite (www.buildoffsite.com).

Both the Avanti and PrOSPa programmes focused their work predominately on the building sector rather than civil engineering. Despite the downturn in the current financial situation in the UK, off-site construction is employed in many large-scale building projects varying from hotels and hospitals to prisons and student accommodation. Certain aspects, such as precast concrete elements, have also been widely employed in the civil engineering sector, but other applications have had little deployment (Gibb, 2001; Goodier and Pan, 2010) and this view was supported by the interviewees in this current survey. Some claimed that the civil engineering sector 'thinks less of their process and data possibly due to the size and duration of the projects' while others debated the reasons for differences. In the building sector, learning from project comparison is less challenging as, for example, the cost of a functional breakdown and the cost of a system from one project to another can be analysed. However, in civil engineering, because of the nature of the work, which is often broken down in different ways and assigned to different subcontractors on site, it is more difficult to compare on either a project-by-project or a contractorby-contractor basis. Some consultants claimed that off-site construction was easier to develop for the building sector due to 'object libraries' and 'catalogues of components', reflecting the repetition in the construction.
Most participants agreed that the building sector is currently leading in implementation of BIM and off-site construction. The main reason was that the software available is more focused on vertical construction. Software providers claimed the building sector has instant gratification from BIM and it is less challenging compared to horizontal infrastructure where segmenting the model is a complex process'. Consultants argued that despite software for the building sector being 'more mature' the real challenges occurred when large geographical areas demand the combined utilisation of geographic information systems and BIM. Government experts claim that less research on processes and data transfers is undertaken by the civil engineering sector, which 'lacks comprehensive data systems, such as industry foundation classes (IFCs)'. Although most firms contributing to this research are involved in large-scale infrastructure projects, only one participant claimed that 'some key civil projects (i.e. Crossrail) are using much more superior BIM techniques than any building project' (Figure 3). To conclude, there was support for the view that the building sector was utilising BIM on a wider scale and was more aware of BIM processes (NBS National BIM Library, 2013), notwithstanding, in civil engineering there were some best practice examples demonstrating the applicability of BIM within a complex infrastructure environment.

All participants agreed that consultants used to lead the way in BIM technologies and methods, 'starting from a position of strength', predominately because of 'their familiarity with the visual aspect of the software and the rapid production of drawings'. During the last few years, contractors have been accelerating their BIM awareness, using it as an opportunity to achieve greater savings. In addition, UK government is a main client of UK contractors and they are being 'forced into rapid BIM implementation' to maintain a competitive advantage. Nevertheless, consultants interviewed claim that contractors use BIM to focus more on the detailed design and the construction phases of the project and less on the operational and the maintenance phases. The UK government representative who was interviewed highlighted the importance of BIM for the life 
Management, Procurement and Law

Volume 167 Issue MP3
Building information modelling

and its effect on off-site

construction in UK civil

engineering

Vernikos, Goodier, Broyd, Robery

and Gibb

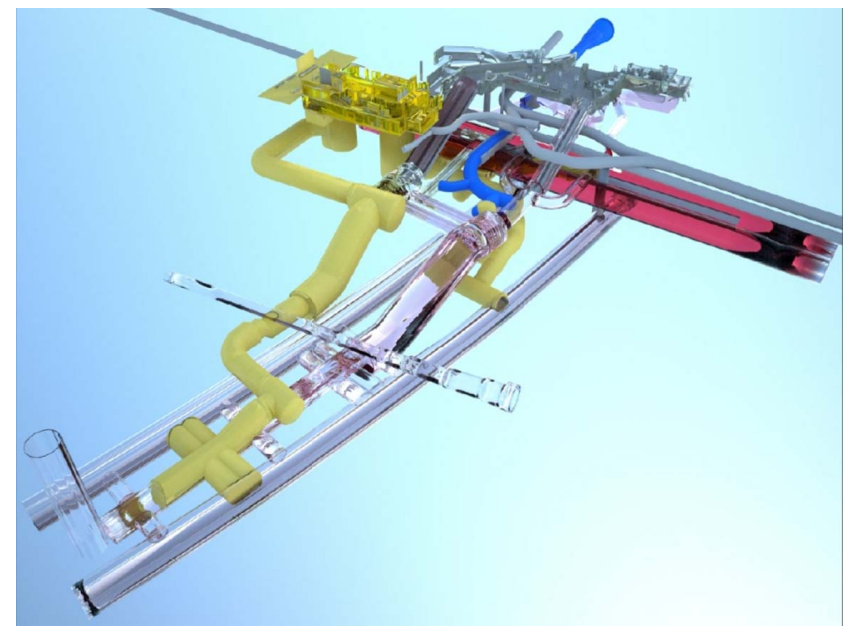

Figure 3. Bond Street station complex BIM model (Vernikos, 2012)

cycle of the project and claimed that the benefits of BIM in the design and construction phases are minimal in comparison.

\section{Discussion}

Considering BIM's effects on off-site construction, most participants thought that, by the UK government mandating BIM by 2016, the usage of off-site construction in the civil engineering sector would increase. Some were very enthusiastic, claiming that off-site construction is the missing link without which there are no easy mechanisms to ensure that design intent is translated into a fabrication intent that is manufactured effectively. In addition, it was claimed that only through BIM 'one that designs precise digital objects can then fabricate them in factory conditions'. Others were more cautious, stating that there are many parameters that determine where and how to use off-site construction but 'BIM helps designers take into account all these factors and make a more informed decision'. Notwithstanding, it was made clear that success depends on how organisations implement BIM and off-site construction in the model they operate. Despite the opinion of most participants that BIM will positively affect off-site construction, one consultant claimed that BIM neither enables nor hinders off-site construction because BIM applies equally to on- and off-site construction work. The consultant believed that, 'off-site construction is on an upward curve and I don't think that curve will become steeper since BIM was formally introduced to the industry'.

\subsection{Configuration management}

As the industry is progressing through an increasingly digitised world, all participants agreed there will progressively be more automation, computerisation and manufacture in construction. The problem currently faced, predominately by contractors, is configuration management. When large numbers of off-site construction components are ordered, the contractors are challenged to locate and identify potentially faulty parts within multiple large and complex construction sites. With BIM, and the technology surrounding it, they claim to be able to track in real time 'which bunch went to which site and from then how many were installed and where'. Therefore, embedding this information in the BIM design gives contractors greater control over off-site construction units, increasing their confidence by reducing risk and so resulting in more adoption of off-site construction. Similarly, consultants claimed that BIM can be used as a site management tool 'that is linked to the actual design of a complex environment with prefabricated units'.

\subsection{Construction management, scheduling and planning}

All contractors claimed that long 'lead-in times' are the greatest disadvantage of off-site construction and, if not managed correctly, choosing off-site construction could add costs to the project and thereby increase risk. To prevent significant delays in the construction phase 'information needs to be accurate, finalised and ready long in advance'. Lead-in times can be managed more effectively within a BIM environment. Contractors claim that BIM enables them to have a better programme that includes the manufacturing process, the delivery and installations linked with the design. Consultants also underline the importance of early scheduling and planning, especially when considering logistics in complex urban construction sites. All participants agreed that the supply chain benefits from timely decision-making through early contractor involvement that is encouraged by BIM, independently of the contractual agreements. Opportunities for off-site construction can be identified and introduced as under a BIM working environment, due to this early decision-making process, 'changes to the design can be made when they are less costly', and 'problems appear earlier'.

The software providers interviewed claimed that 'BIM gives the opportunity for a continuum data sharing in a live design environment' and see BIM as a trigger for leveraging the model throughout the process so that the design gets analysed, confirmed and used automatically by machinery to fabricate off-site construction components. Contractors and consultants partially agree that more reliable information would be provided to the off-site construction suppliers and fabricators and therefore less re-work would occur due to this 'BIM-offsite link'. Contractors argued that a high level of design is necessary for manufactured components, making it clear that they 'need to be sure that the components they order or prefabricate will fit and will be assembled as the design indicates'. With BIM they claim to be able to assemble the structure virtually, observing the process before it starts onsite. Overall, the participants thought that

first, through a better quality of information, their current off-site construction use will be improved and will 
Management, Procurement and Law

Volume 167 Issue MP3
Building information modelling

and its effect on off-site

construction in UK civil

engineering

Vernikos, Goodier, Broyd, Robery

and Gibb consequently result in better quality off-site construction being produced

second, better communications, triggered by BIM, will identify more opportunities for such solutions.

\subsection{Interface management and information data flow}

BIM was seen by most participants as 'a good platform to engage different sectors and improve business-to-business relations in order to explore and benefit from opportunities'. All contractors perceived BIM to promote collaboration in the earlier life of the project, which is necessary for off-site construction implementation (Gibb, 2001). Contractors are adamant that BIM will help establish relationships and then those relationships will help identify potential for off-site construction. They predict 'more and more organisations joining to design and construct together', therefore creating more sophisticated solutions through these combined processes. Consultants also thought that BIM encourages coordination of different parties and departments to understand 'who is doing what, when'. Examples were discussed where 'during design meetings using BIM 3D models, the dynamics of the communication changed and less time was spent describing problems and more time was spent trying to solve them'. The participants believe that working under a BIM environment was a way to be 'exposed' to areas where off-site construction could be 'a better option'.

All participants considered the way information is currently communicated in the construction industry to be a big issue. There are "very abrupt handovers of information, usually in document form', which need continuous checking. Minor mistakes in design or misprints could lead to an increase in cost and construction time, especially when using off-site construction, as there is little or no flexibility when the components arrive on site. Some participants thought there is insufficient checking in civil engineering. This is because "the disruption to the team when someone is taken off the process to check the drawing and documents is huge'. Consultants believe that BIM affects the integration of the design team, so it is important to have good information flow throughout the supply chain. BIM with a shared working platform might provide a shared space where every change is tracked and is visible by colleagues and by other teams. BS1192 (BSI, 2007) makes a distinction between someone's private work, the shared work in progress and the published work. Within that 'shared' environment, automatic checking and peer review is viable, allowing issues to be identified in advance and discussed earlier in the process. This allows a continuous discussion and progression without abrupt information handovers and catastrophic 'start-stop' checking procedures. However, participants were unable to supply evidence of current projects working as described above. Some examples were discussed but little substantiation was provided.

\subsection{Procurement and contract}

Contractual agreements and procurement under a BIM environment is at the forefront of the government's agenda. Many participants believed that 'BIM should be a catalyst for changing the way the industry procures'. All participants thought that the current procurement methods hinder the development of off-site construction through BIM. Contractors thought that procurement mechanics can really affect the development of off-site construction and highlighted that 'design and build contracts enable BIM driven off-site construction'. Consultants agree that early contractor involvement 'can help to identify when off-site construction can be of value' therefore appropriate contractual agreements will enable 'earlier' decisions, which is 'the key' to successful implementation. Consultants also believe there is a problem when models, drawings and other data are produced but circulated as 'only for information, do not use'. All parties agree that producing data through BIM comes with a great responsibility, as mistakes are easily identified and traced. Consequently contracts need to include the required quality of information and state every party's responsibility, accountability and liability facilitating more clarity; this would result in an increase in confidence that would encourage or 'invite' innovative off-site construction solutions. Reviewing the principles and assumptions of BIM (BuildingSMART, 2011), it only seems to work when fully within a collaborative contractual environment. Failure to acknowledge this limitation may adversely affect the successful implementation of BIM across the industry.

\subsection{Object-oriented design: virtual objects, virtual libraries and assemblies}

The software experts claimed that current BIM software is 'not that great for assemblies'. Currently, existing software does not allow, practically and in any automated form, identification of opportunities for off-site construction more than in the old document and drawing-based design' and construction process. However, BIM has the potential to promote off-site construction by identifying repetition, which will enable greater cost-saving through mass customisation. BIM should 'be more about information, productivity, re-usability and one input - many outputs but there should be more automation within the model to identify and promote areas for further cost reduction from economies to scale through off-site construction'. Examples were discussed from abroad (Singapore) where a decade ago, a system was introduced in which a BIM model could be checked against building regulations and planning permission automatically online. According to the UK government participant, the 'technology alliance group' is currently tasked by UK government to challenge the way software vendors allow 'BIM libraries' to be created or other ways of grouping components or systems. 'The real challenge is on the way the software will manage assemblies, what kind of assemblies may occur, what kind of components they may contain and how can they be shared'. 
All 'BIM authoring tools' and 'information transfer protocols', such as construction operations building information exchange (COBie) and IFCs can be used to share assemblies, even though a series of problems occur that software developers and UK government task groups are trying to address. The UK government appreciates the potential for off-site construction and they are aware of its documented advantages, but they are not willing to 'regulate or demand' a specific software or technology to promote it, saying 'the UK government, as a client, gave COBie to the supply chain and it is up to them to respond accordingly'. The challenges include the following situations.

The type of functions or technology that will be used by the application to create and save off-site construction components as a library resource.

- 'Once one has created these assemblies, how would the attributes and classifications work?' The key issue is whether the assembly will override the content or vice versa: for example, could an assembly get scheduled without the content, or could the content get scheduled but not the assembly?

- Exporting and sharing assembly data in a BIM environment is considered by respondents to be an issue despite the implementation of COBie and IFCs. BS8541 (BSI, 2012) was created to assist in this 'computerised data exchanging environment' aiming to encourage manufactures of off-site construction components to recommend designs, fix costs and demonstrate the quality of their products through a 'template'. Nevertheless, 'manufacturers are wary of this process as the information required from them is not clear and intellectual property issues arise'. The 'templates' mentioned in BS8541 (BSI, 2012) were criticised as having 'a lot of attributes but no values'.

Civil engineering contractors criticise the existing practices, claiming that most of the software and the processes accompanying them are mainly relevant for the building sector. They have experience of software that allows 'partial grouping' for the creation of assemblies of components. Some contractors are investigating the potential for BIM and off-site construction, aiming to create an internal four-dimensional installation manual. This 'catalogue' will contain lists of components including detailed costing, installation and material properties. The design staff will then be able to choose and order a component for manufacture. The tool will have the capability to 'show how the structure will come together'. The contractor developing this 'virtual design catalogue' admits that very little is directed towards the civil engineering sector.

Consultants also agree that the 'software right now focus primarily on onsite building work rather than off-site construction'. They claim that software is not appropriate for creating different prefabricated objects or elements with different materials and layers. When there is a need to create such objects they will use software and 'export the models to the software used by the BIM platform'. Other consultants discussed additional issues with object libraries. If assemblies are used, on a project-to-project level, the definitions and the shared libraries have to be identified otherwise there are problems with definitions of elements and identifying quantities of elements or components.

Software providers admit that 'the software is in a maturing stage', but they claim to be working hard on preparing standards and facilities for custom component preparation to facilitate assemblies, parametric objects that represent building components. They understand that it is 'an area that is evolving' and they are finding it very difficult to standardise civil engineering components to segregate or subdivide the linear horizontal assets. Examples were discussed focusing on mature assembly systems (i.e. drainage) that have already been standardised, and software providers claim the modelling of such off-site construction systems can be much more efficient through any BIM technology.

\subsection{Modelling: modelling capabilities, model quality and data richness}

All participants claimed that BIM enables off-site construction because of the three-dimensional (3D) elements that allow greater visualisations. Nevertheless, increasingly, some contractors find that when models are received after the tender, the actual 'BIM model' has very little value in it. So 'at times we have to re-model because the designer models in a way that does not reflect the way that the project will be built'. The model is vital for construction programming and therefore the designer has influence in that process and is the key for lead-in times when considering off-site construction construction. Once again contractors claim the problem lies with the procurement process and the contractual agreement. Contractors admit that 'the contractor fraternity is still asking for 2D drawings' and examples were discussed where consultants designed in 3D and were asked to 'cut the drawing in 2D for the constructor to understand it', which was deemed 'counterproductive' by both parties. Consultants argue that 'the $2 \mathrm{D}$ mentality from the constructors' side has to change' and the contractors interviewed agreed with this statement.

An area of great debate is the way modelling or designing skills affect the identification of off-site construction in a BIM environment. Some contractors claim that there are examples of some designers who struggle "with the technology and at that point BIM becomes a hindrance not just to off-site construction but for the construction process itself'. Meanwhile, other contractors admit that the 'tools' have great capabilities and 'are far beyond their current abilities to use them to their full 
Management, Procurement and Law

Volume 167 Issue MP3
Building information modelling

and its effect on off-site

construction in UK civil

engineering

Vernikos, Goodier, Broyd, Robery

and Gibb potential', indicating a training skills gap. Most contractors felt the ability of the 'software operator' to identify opportunities for off-site construction is crucial and therefore 'software operators' in a BIM environment 'have to be engineers rather than technicians'. The contractors were insistent that as the 'designer plays a vital part in the construction process as they construct the project virtually - therefore it is an engineer's job'.

In contrast, consultants claim that there is no need for complex training in order to operate the BIM software correctly. They believe 'inter-tier communications' are crucial to ensure that skilled technicians are using the correct information, library or layer. Responding to the contractors' view about designer BIM capabilities, consultants believed engineers need only be aware of the software's capabilities and 'operate it for everyday tasks', but nevertheless a 'modelling champion' that specialises in the software will always be required to do complex aspects of projects.

The software providers believe that the operator is responsible for using the software correctly in order to be able to 'identify quantifications for off-site'. Some examples discussed included the use of BIM to subdivide a design into components that will significantly reduce logistic and installation problems due to the size or height of the component.

\section{Conclusion}

Both BIM and off-site construction as concepts are not fundamentally new, but terms referring to the ideas have changed over the decades to reflect industry trends. During the past few years a number of successful case studies on the use of off-site construction within a BIM environment have been published (Eastman et al., 2011). The majority of these are focused on the building sector, with the USA leading BIM implementation. Within the UK, early adopters such as the Ministry of Justice are using BIM with off-site construction for prison blocks and some 'best practice' examples are producing promising results (MoJ, 2013).

Despite high expectations from the literature and some practical success in the building sector, very limited application of off-site construction through BIM is witnessed in civil engineering. The participants in this research attempted to identify evidentiary examples to prove that BIM enables, promotes, increases or improves off-site construction, but apart from some aspects of 'key infrastructure projects', no evidence could be provided. The UK government provided examples in which 'projects started using BIM from RIBAStage C (concept) phase and this was deemed fundamentally flawed'. Therefore, based on this principle, some participants' examples were disregarded as their 'BIM' elements were merely $3 \mathrm{D}$ visuals or the BIM implementation was encouraged not for its efficiencies but for commercial reasons. When participants were not able to provide evidence, they claimed that the statements were going to materialise during BIM level 3. Nevertheless, as the UK government confirmed during the interview, currently BIM level 3 is yet to be clearly defined.

Off-site construction is a more 'familiar' concept to the civil engineering sector than BIM, with precast concrete elements and bridge construction or tunnelling often employing off-site construction (Vernikos et al., 2012). However, throughout the data collection process of the research summarised in this paper there is a confusion of the terms 'standardisation' with 'prefabrication' and the term 'off-site construction' was not clearly understood. Economies of scale are achievable through standardising off-site construction elements and BIM may influence the process drastically, yet the one does not automatically lead to the other. 'Standardisation is an aspect of BIM, but a minor percentage of civil engineering works is standardised' as parametric and logistical flexibility is needed. With consultants saying that 'contractors don't know what they want' and contractors claiming that consultants give them 'empty models' the confusion is not limited to off-site construction terminology but also to BIM implementation.

After analysing the responses of 12 of the BIM and innovation directors representing leading UK consultants, contractors, software vendors and construction industry institutions, it is evident that there is a clear belief that BIM will improve and increase off-site construction construction in civil engineering. Nevertheless, there is still very little proof that this is currently the case. It appears from the findings presented here that BIM does have the potential to improve the quality of existing offsite construction methods and solutions, although investment will be needed in training to get the best out of the complex software. Once this is in place, it may raise industry confidence and therefore it could indirectly increase the off-site construction usage overall.

\section{REFERENCES}

Bew M and Underwood J (2009) Delivering BIM to the UK market. In Handbook of Research on Building Information Modelling and Construction Informatics: Concepts and Technologies. IGI-Global, New York, NY, USA, pp. 30-64.

Blismas NG, Pendlebury MC, Gibb AGF and Pasquire CL (2005) Constraints to the use of off-site production on construction projects. Architectural Engineering and Design Management 1(3): 153-162.

BSI (2007) BS 1192:2007. Collaborate production of architectural, engineering and construction information Code of practice. BSI, London, UK.

BSI (2012) BS 8541-1:2012. Library objects for architecture, engineering and construction. Identification and classification - Code of practice. BSI, London, UK.

BSI (2011) Constructing the Business Case for BIM. 
International Alliance for Interoperability. BSI, London, UK.

Cassell C and Symons G (2004) Essential Guide to Qualitative Methods in Organisation Research. Sage Publications, London, UK.

Construction Project Information Committee (2007) AVANTI: ICT-Enabled Collaborative Working. See www.cpic.org.uk/ en/publications/avanti/ (accessed 24/06/2013).

Eastman C. and Sacks R (2008) Relative productivity in the AEC industries in the United States for on-site and off-site activities. Journal of Construction Engineering Management 134(7): 517-526.

Eastman C, Teicholz P, Sacks R and Liston K (2011) BIM Handbook: A Guide to Building Information Modeling for Owners, Managers, Designers, Engineerings and Contractors, 2nd edn. John Wiley, Hoboken, NJ, USA.

Gibb AGF (2001) Standardization and pre-assembly: distinguishing myth from reality using case study research. Construction Management and Economics 19(3): 307-315.

Glaser B and Strauss AL (1967) The Discovery of Grounded Theory. Aldine, Chicago, IL, USA.

Goodier C and Gibb AGF (2007) Future opportunities for offsite in the UK. Construction Management and Economics 25(6): 585-595.

Goodier Cl and Pan W (2010) The Future of UK Housebuilding. RICS, London, UK.

Hu Q and Quan J (2005) Evaluating the impact of IT investment on productivity: a causal analysis at the industry level, International Journal of Information Management 25(1): 39-53.

Larsson J and Simonsson P (2012) Barriers and drivers for increased use of off-site bridge construction in Sweden. Proceedings of the 28th Annual ARCOM Conference, Edinburgh, UK. Association of Researchers in Constrution Manaement, Edinburgh, UK, pp. 751-761.

McGraw Hill Construction (2010) Smart Market Report: The Business Value of BIM in Europe. McGraw-Hill Construction, Bedford, MA, USA.

McGraw Hill Construction (2011) Smart Market Report: Prefabrication and Modularisation - Increasing Productivity in the Construction Industry. McGraw-Hill Construction, Bedford, MA, USA.

Miles J and Whitehouse N (2013) Offsite Housing Review. Department of Business, Innovation \& Skills and the Construction Industry Council, London, UK.

MoJ (Ministry of Justice) (2013) Early Adopters Project HMYOI Cookham Wood: New House Block and Education Building, BIM Lessons Learnt, Report Version 3. See http://www. bimtaskgroup.org/wp-content/uploads/2012/03/CookhamWood-Consolidated-Lessons-Learned-version3-with-intro. pdf (accessed 06/06/2013).

Morrell P (2011) BIM: A Report for the Government Construction Client Group. Department for Business, Innovation and Skills, London, UK.
Murray M and Langford D (2003) Construction Reports 1944-98. John Wiley, Oxford, UK.

Nadim W and Goulding J (2010) Offsite production in the UK: the way forward? A UK construction industry perspective. Construction Innovation: Information, Process, Management 10(2): 181-202.

NBS National BIM Library (2013) National BIM Report 2013. RIBA Enterprises, London, UK.

Strauss A and Corbin J (1990) Basics of Qualitative Research: Grounded Theory Procedures and Techniques. Sage Publications, Newbury Park, CA, USA.

Venables T, Barlow J and Gann D (2004) Manufacturing Excellence: UK Capacity in Offsite Manufacturing. Constructing Excellence, Housing Forum, London, UK.

Vernikos VK (2012) Optimising building information modelling and off-site construction for civil engineering. Proceedings of the Institution of Civil Engineering - Civil Engineering 165(4): 147.

Vernikos VK, Goodier Cl, Gibb AGF, Robery PC and Broyd TW (2011) Offsite innovation in UK infrastructure: the role of the approvals process in box jacking projects. Proceedings of the 27th Annual ARCOM Conference, Bristol, UK. Association of Researchers in Constrution Management, Bristol, UK, pp. 53-62.

Vernikos VK, Goodier Cl, Gibb AGF, Robery PC and Broyd TW (2012) Realising offsite construction and standardization within a leading UK Infrastructure consultancy. Proceedings of the 7th Annual AEC Conference, Sao Paulo, Brazil. Escola Politécnica, University of São Paulo, Brazil, UK, pp. 68-77.

Wix J (1997) Information models and modelling: standards, needs, problems and solutions. The International Journal of Construction Information Technology 5(1): 27-38.

Wolstenholme A (2009) Never Waste a Good Crisis: A Review of Progress since Rethinking Construction and Thoughts for Our Future. Constructing Excellence, London, UK.

Wordle (2013) See http://www.wordle.net/ (accessed 24/06/ 2013).

\section{WHAT DO YOU THINK?}

To discuss this paper, please email up to 500 words to the editor at journals@ice.org.uk. Your contribution will be forwarded to the author(s) for a reply and, if considered appropriate by the editorial panel, will be published as discussion in a future issue of the journal.

Proceedings journals rely entirely on contributions sent in by civil engineering professionals, academics and students. Papers should be 2000-5000 words long (briefing papers should be 1000-2000 words long), with adequate illustrations and references. You can submit your paper online via www.icevirtuallibrary.com/content/journals, where you will also find detailed author guidelines. 